\title{
Quick Judgments of Properties of Fine Aggregate to Use the Electric Arc Furnace Oxidizing Slag
}

\author{
Lee, Hyung-Min ${ }^{1 *} \quad$ Lee, Han-Seung ${ }^{2} \quad$ Choi, Jae-Seok $^{3}$ \\ Department of Sustainable architectural engineering, Han yang University, Ansan, Korea ${ }^{1}$ \\ Department of Division of architecture Han yang University, Ansan, Korea ${ }^{2}$ \\ Korea Conformity Laboratories, Ochang, Korea ${ }^{3}$
}

\begin{abstract}
Blast furnace slag is recycled as a high value-added material, while steel slag is difficult to recycle or is recycled as a low-grade filler material due to its expansive characteristics. Its property is caused by the high content of free lime and instable steel oxides. Recently, an innovative and rapid cooling method for melting steel slag has been developed in Korea, which reduces free lime content to a minimum level and increases the stability of steel oxides. However, researches on the long-term stability are not sufficient so far. Therefore, this study, focusing on the electric arc furnace oxidizing slag in the steel slag, aims to investigate the properties of the steel slag aggregate, its long-term volume stability and the engineering strength of mortar, and using it as a fine aggregate. This study result indicated that it was possible for it to be used as concrete aggregate because the volume change of the steel slag appeared to be stable.
\end{abstract}

Keywords : electric arc furnace, oxidizing slag, expansion, autoclave

\section{Introduction}

\subsection{Purpose}

The steel industry not only uses many of raw materials and energy due to the features of its manufacturing process. but also generates various kinds of by-products and waste. The slag is the by-product that takes the largest quantities, and steel slag was generated in a total of 18,666,000 tons in 2007, an increase of $6.5 \%$ compared with the previous year. Among them, blast furnace slag and electric arc furnace slag are generated in the

Received : April 8, 2011

Revision received : September 4, 2011

Accepted : September 6, 2011

* Corresponding author : Lee, Han-Seung [Tel: 82-31-400-5181, E-mail: ercleehs@hanyang.ac.kr]

(c2011 The Korea Institute of Building Construction, All rights reserved. quantities of 9,501,000 tons and 5,396,000 ton, respectively, with electric arc furnace slag in the quantity of 3,707,000 tons[1,2].

No clear use of recycling was prepared for such electric arc furnace slag in the area of construction. The standard for use of fine aggregate of electric arc furnace oxidizing slag for concrete was presented at KS F 4571 for electric arc furnace oxidizing slag among electric arc furnace slags, but coarse aggregates have been used without the separate regulation[3].

However, in Japan, JIS A 5011-4 Electric Arc Furnace Oxidizing Slag Aggregate specifies that it can be used as slag aggregate for concrete[4,5]. In general, electric arc furnace slag produces electric arc furnace oxidizing slag(hereinafter, EOS) and electric arc furnace reducing slag(hereinafter, ERS) together. While it is known that electric arc furnace slag has the feature of expansion feature, there will 
be no problem in using it if it is based on the separate discharge of ERS with expansion.

Accordingly, this study examined the possibility of using the EOS aggregate as aggregate for concrete through a test on physical and chemical features of EOS and ERS in order to suitably use EOS aggregate. It took about 10 days to perform a $80{ }^{\circ} \mathrm{C}$ submerged expansion experiment executed to determine the expansion degree of EOS currently. It aimed for the quick evaluation technology of determining the slag expansion by finding the method to advance the time required.

\section{Feature of Electric Arc Furnace Slag}

\subsection{Creation Process of EOS and ERS}

The iron materials are charged to the electric arc furnace and arc is generated between electrodes to heat and fuse the scrap metal materials and to refine them to the steel by a reaction that occurs while it passes through an oxidizer and reductor. Oxidizer infuses air to steel to oxidize silicon, carbon, hydrogen and phosphorus among iron materials.

The oxidizer infuses oxygen to steel to oxidize silicon, carbon, hydrogen and phosphorous among steel elements and the remains become carbon monoxide and water. Oxidizing slag is the fusion of limestone, quicklime, silicon and iron charged to the vaporizing oxides as subsidiary materials.

At this time, parts of refractory such as magnesia used on the furnace wall are eluted, parts of iron and manganese are oxidized, forming elements of oxidizing slags.

Reducing slag is created by removing and desulfurizing the oxygen exceeded from the reducer under the reducing environment at the same time by charging quicklime again after discharging oxidizing slag from electric arc furnace. While reducing slag has low oxides such as iron, manganese or phosphorus, it contains substances such as free lime(Free-CaO) that cannot fix the elements in the large quantities [6].

Table 1. Kind of steel slag

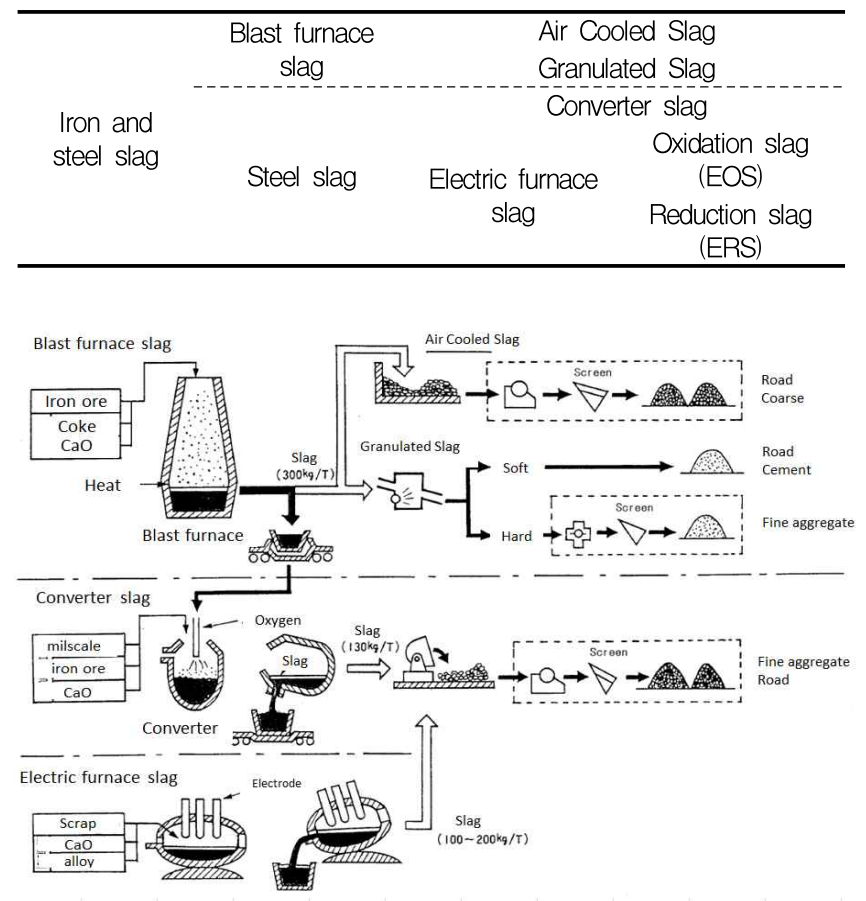

Figure 1. Production process of steel slag

\subsection{Expansion Mechanism of electric arc furnace slag}

Unstable elements among electric arc furnace slag can be divided into free lime(Free-CaO) and free magnesium(Free-MgO) and It is reported that electric arc furnace slag expands or collapses due to this. Among them, the expansion collapse by hydration of free lime is the representative of that of electric arc furnace slag. Such free lime is generated as quicklime(CaO) and used as subsidiary materials for refining steel materials such as pig iron or scrap iron which are not sufficiently slagged. It sometimes remains in the slag in its stable status. Such unstable lime is called free lime. If it reacts with water, it reacts as shown in the following formula (1) so that volume increases about two times and bring about the expansion of slag $[7,8,9]$.

Free- $\mathrm{CaO}+\mathrm{H}_{2} \mathrm{O} \rightarrow \mathrm{Ca}(\mathrm{OH})_{2}$ 
Free- $\mathrm{CaO}$ reacts with water and creates an alkali compound of $\mathrm{Ca}(\mathrm{OH})_{2}$, which include the environmentally aggravating factors such as seawater and air pollution, which causes chemical weathering, restricting the use of electric arc furnace slag consequently. Among them, electric arc furnace reducing slag shows expansion but oxidizing slag is found to have almost no expansion.

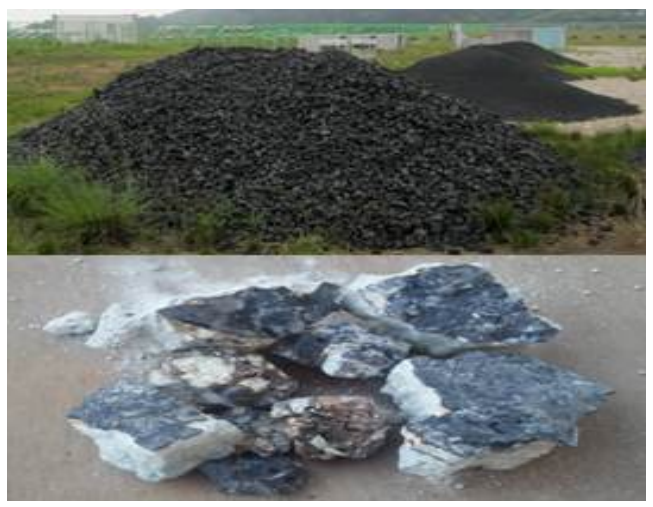

Figure 2. EOS and ERS aggregate

According to JIS A 5011, the amount of Free-CaO in the slag aggregate decreases if the basicity within JIS A 5011-4 specification scope is less than 2.0 as shown in Figure 3[10].

Figure 4 shows the relation between the basicity and the length variation of concrete. It is clear that the variation of concrete gradually decreases when the basicity is within JIS A 5011-4 specification scope. Accordingly, it expands when the basicity is within specification scope of JIS A 5011 and the basicity is over 2.0.

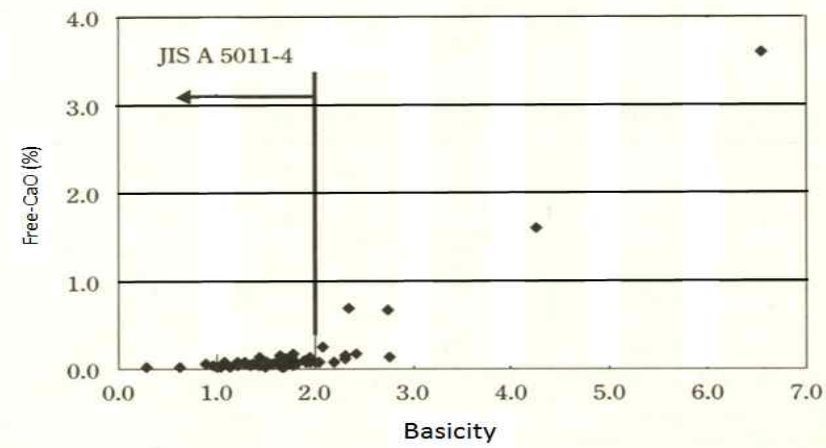

Figure 3. Between basicity and free-cao of EAF

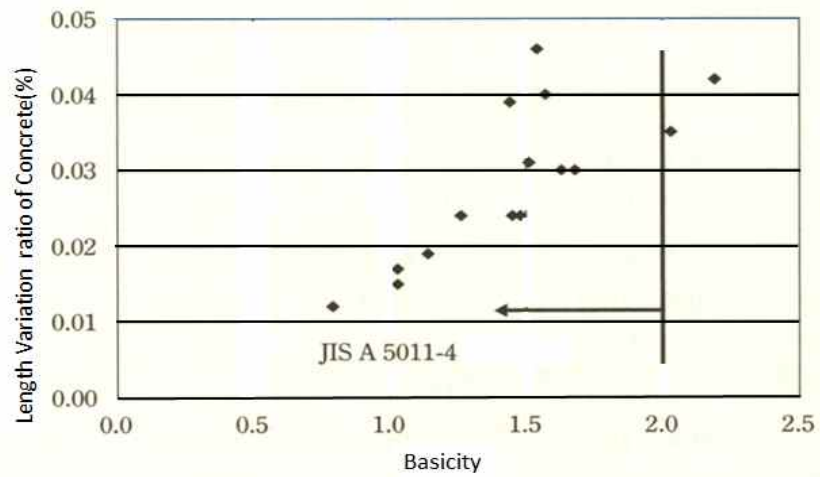

Figure 4. Between basicity and length variation ratio of concrete

\section{Experiment Plan and Method}

\subsection{Overview of Experiment}

To examine the physical and chemical features of EOS, a mortar specimen was manufactured using EOS and ERS fine aggregates in items of the physical features as shown in the Table 2, and compressive strength, the immersion expansion and autoclave experiments were performed. XRF was examined to check the chemical composition as the chemical feature.

Table 2. Experiment item

\begin{tabular}{ccc}
\hline Type & Test Item & Test method \\
\hline & $\begin{array}{c}\text { Compressive } \\
\text { strength } \\
\text { Immersion } \\
\text { expansion in 80 } \\
\text { Physical properties }\end{array}$ & KS L ISO 679 \\
& KS F 2580 & \\
Autoclave test & KS L 5107 \\
Chemical properties & XRF \\
\hline
\end{tabular}

\subsection{Materials}

\subsubsection{Cement}

The cement used for the compressive strength experiment is ordinary portland cement(OPC) of Korean S company. Its physical properties are as 
shown in Table 3 including density of $3.15 \mathrm{~g} / \mathrm{cm}^{3}$. Chemical composition are as shown in Table 4.

Table 3. Physical properties of cement

\begin{tabular}{cccccc}
\hline \multirow{2}{*}{$\begin{array}{c}\text { Type of } \\
\text { Cement }\end{array}$} & Density & $\begin{array}{c}\text { Fineness } \\
\left(\mathrm{cm}^{2} / \mathrm{g}\right)\end{array}$ & \multicolumn{3}{c}{ Compressive strength $\left(\mathrm{Kgf} / \mathrm{cm}^{2}\right)$} \\
\cline { 4 - 6 } & & & 3 Day & 7 Day & 28 Day \\
\hline OPC & 3.15 & 3300 & 30 & 42 & 58 \\
\hline
\end{tabular}

Table 4. Chemical composition of material (\%)

\begin{tabular}{cccccccc}
\hline & $\mathrm{CaO}$ & $\mathrm{SiO}_{2}$ & $\mathrm{~A}_{2} \mathrm{O}_{3}$ & $\mathrm{MgO}$ & $\mathrm{Fe}_{2} \mathrm{O}_{3}$ & $\mathrm{SO}_{3}$ & $\mathrm{MnO}$ \\
\hline Cement & 57.41 & 20.89 & 3.55 & 3.11 & - & 3.50 & - \\
EOS & 19.88 & 20.63 & 9.41 & 4.87 & 34.71 & - & 6.74 \\
ERS & 29.61 & 13.97 & 10.50 & 3.05 & 39.13 & - & 3.17 \\
\hline
\end{tabular}

\subsubsection{Fine Aggregate}

EOS used for the experiment is the 'I' aggregate of Incheon among I,A,B producing district. Table 4 shows the chemical composition of electric arc furnace slag oxides. $\mathrm{CaO}, \mathrm{Fe}_{2} \mathrm{O}_{3}, \mathrm{SiO}_{2}, \mathrm{MgO}, \mathrm{Al}_{2} \mathrm{O}_{3}$ are the main elements of EOS and ERS. Table 5 shows the physical properties of EOS.

Table 5. Physical properties of EOS

\begin{tabular}{cccc}
\hline Item & I & A & B \\
\hline $\begin{array}{c}\text { Size } \\
(\mathrm{mm})\end{array}$ & 5 & 5 & 5 \\
$\begin{array}{c}\text { Surface dry } \\
\text { density }\left(\mathrm{g} / \mathrm{cm}^{2}\right)\end{array}$ & 3.70 & 3.38 & - \\
$\begin{array}{c}\text { Specific gravity under } \\
\text { oven-dry }\left(\mathrm{g} / \mathrm{cm}^{2}\right)\end{array}$ & 3.68 & 3.35 & - \\
F.M & 2.71 & 2.54 & - \\
$\begin{array}{c}\text { Absorption } \\
\text { factor(\%) }\end{array}$ & 1.1 & 2.0 & 2.50 \\
\hline
\end{tabular}

\subsection{Items of Measurement}

\subsubsection{Compressive Strength Experiment(KS L ISO 679)}

The compressive strength experiment of mortar according to KS L ISO 679 was conducted using the ISO standard sand of fine aggregate, ERS fine aggregate and EOS fine aggregate of Incheon 'I' company in the mixture rate shown in the Table 6 [11]. ERS was mixed by replacing EOS with the ratio of $9: 1,8: 2$ and $7: 3$. This experiment is to examine the optimal mixing that does not affect the expansion after mixing ERS with expansion and EOS without expansion. The compressive strength experiment was performed on each specimen using universal test machine(UTM) after immediately removing the specimen that went through air-dry curing for 24 hours after mixing experiment.

Table 6. Composition of mortar mixtures

\begin{tabular}{ccccccc}
\hline \multirow{2}{*}{ W/C } & Mixture & C(g) & \multicolumn{4}{c}{ S } \\
\cline { 3 - 6 } & & & $\begin{array}{c}\text { ISO- } \\
\text { Sand(g) }\end{array}$ & $\begin{array}{c}\text { EOS } \\
(\mathrm{g})\end{array}$ & $\begin{array}{c}\text { ERS } \\
(\mathrm{g})\end{array}$ & $(\mathrm{g})$ \\
\hline \multirow{4}{*}{0.5} & ISO-Sand & 1920 & 5760 & - & - & 960 \\
& EOS & 1920 & - & 5760 & - & 960 \\
& ERS 10 & 1920 & - & 5184 & 576 & 960 \\
& ERS 20 & 1920 & - & 4608 & 1152 & 960 \\
& ERS 30 & 1920 & - & 4032 & 1728 & 960 \\
\hline
\end{tabular}

\subsubsection{Basicity Analysis of EOS and ERS}

For chemical analysis of expansion of EOS and ERS, the amounts of $\mathrm{CaO}$ and $\mathrm{SiO}_{2}$ element in the aggregate were measured through XRF analysis and basicity of EOS and ERS of Incheon 'I' company was measured.

Table 7 shows the chemical components and physical property standards of EOS. According to JIS A 5011, it was based on the determination that the aggregate was stable if the amount of $\mathrm{CaO} / \mathrm{SiO}_{2}$ is less than 2.0.

Table 7. Standard of EOS property

\begin{tabular}{cc}
\hline Item & EOS \\
\hline $\mathrm{CaO}(\%)$ & Below 40.0 \\
$\mathrm{MgO}(\%)$ & Below 10.0 \\
$\mathrm{FeO}(\%)$ & Below 50.0 \\
$\mathrm{CaO} / \mathrm{SiO}_{2}$ & Below 2.0 \\
\hline
\end{tabular}




\subsubsection{Autoclave Expansion Experiment(KS L 5107)}

The autoclave experiment is to subject the specimen to high temperature and high pressure. It was used here to examine the expansion rate of electric arc furnace slag.

Specimens (9 test pieces) in a cement length variation mold were placed in a humidity chamber for 24 hours like the autoclave specimens and equipment in Figure 5 according to the autoclave expansion test method of KS L5107 cement. Then the specimen length was measured, autoclave tested, and the specimen length was measured after drying[12].

The pressing time of autoclave was separated into 12 hours, 24 hours, 36 hours and 48 hours and measured until the expansion stopped.

For the calculation of the slag expansion rate, 3 specimens were created and tested, and their averages were calculated. Autoclave expansion of cement was also reported by calculating the length difference of specimen before and after test up to $0.01 \%$ of effective marking length.
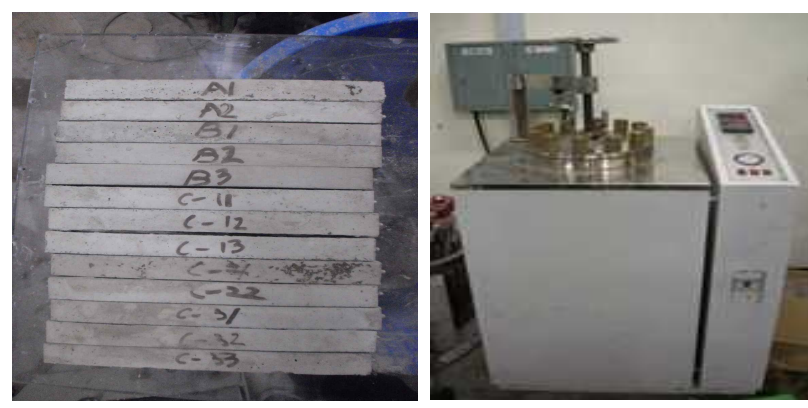

Figure 5. Specimens and equipment for autoclave test

\subsection{4 $80{ }^{\circ} \mathrm{C}$ Immersion Expansion of EOS and ERS}

$80{ }^{\circ} \mathrm{C}$ Immersion Expansion experiment of steel slag according to KS F 2580 is the test method to measure the expansion stability of slag[13]. This method is currently executed to evaluate the expansion of EOS, and measures the length of the specimen for 10 days to determine the expansion.

After producing the specimen as shown in Figure
6, submerge it in the curing bath and record the first reading of dial gauge. Then, for curing, keep in the chamber of at $80 \pm 3{ }^{\circ} \mathrm{C}$ for 24 hours, and lower the temperature to room temperature. Repeat the measurement of for immersion expansion once a month for 10 days and measure the length change under the same conditions. Calculate the immersion expansion ratio by the following formula (2).

$$
\gamma_{e}=\frac{D_{F}-D_{S}}{H} \times 100----------(2)
$$

where,

$\gamma_{e}$ : Immersion Expansion Ratio(\%)

$D_{F}$ : final scale of dial gauge(mm)

$D_{S}$ : initial scale of dial gauge $(\mathrm{mm})$

$H$ : first height of specimen $(\mathrm{mm})$
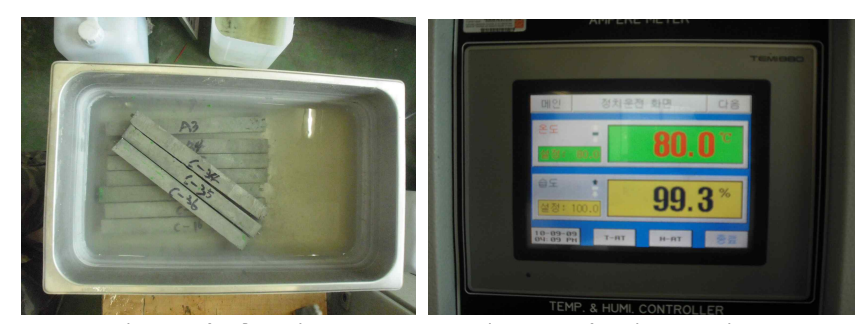

Figure 6. Specimens and equipment for immersion expansion in $80{ }^{\circ} \mathrm{C}$ water

\section{Experiment Results and Conclusions}

\subsection{Compressive Strength}

For the results of the compressive strength experiment of mortar specimen of EOS and ERS, compressive strengths of EOS and ERS mortar as well as standard sand from 3 days to 28 days were measured as shown in the Figure 7 and Table 8. The case that electric arc furnace oxidizing slag was used was most excellent with $43.2 \mathrm{Mpa}$. In addition, when 10 \% was added in ERS with expansion, it shows the higher strength than that of mortar using the standard sand.

It means that electric arc furnace slag is perfectly rounded shape and is considered to be the steel 
element that appears when electric arc furnace slag occurs.

Table 8. Compressive strength of mortar (Mpa)

\begin{tabular}{cccc}
\hline & 3 Day & 7 Day & 28 Day \\
\hline ISO-Sand & 19.0 & 27.2 & 35.0 \\
EOS & 29.6 & 34.1 & 43.2 \\
ERS 10 & 30.8 & 37.8 & 41.4 \\
ERS 20 & 27.2 & 33.7 & 40.4 \\
ERS 30 & 25.4 & 32.6 & 39.4 \\
\hline
\end{tabular}

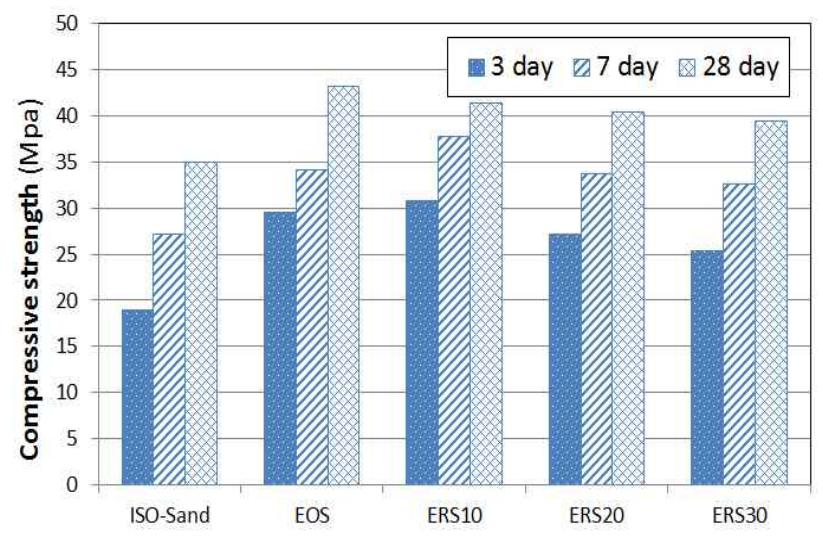

Figure 7. Compressive strength of mortar (Mpa)

\subsection{Basicity Analysis}

It was expressed using the chemical component comparison XRF of electric arc furnace EOS and ERS. According to JIS A 5011, XRF expansion in aggregate occurs if the basicity is over 2.0 as a result of chemical element analysis.

Table 9 shows the basicity of EOS and ERS in comparison to each other. Since the basicity of EOS is 0.96 and satisfies the conditions of JIS A 5011 under the basicity 2.0, it is considered to have low expansion. On the other hand, since the basicity of electric arc furnace $\mathrm{ERS}$ is 2.12, recording expansion with basicity over 2.0, EOS has no expansion than ERS, and is proven to be stable with the XRF chemical analysis.
Table 9. Between basicity EOS and ERS

\begin{tabular}{cc}
\hline Type & Basicity $\left(\mathrm{CaO} / \mathrm{SiO}_{2}\right)$ \\
\hline EOS & 0.96 \\
ERS 10 & 0.98 \\
ERS 20 & 1.01 \\
ERS 30 & 1.03 \\
ERS 100 & 2.12 \\
\hline
\end{tabular}

\subsection{Comparison of Autoclave Expansion}

With regard to autoclave expansion according to KS L 5107, the length variation was measured until expansion stopped with the mortar length variation dial gauge as shown in measurement of expansion of specimen in Figure 8 using EOS and ERS mortar specimen.

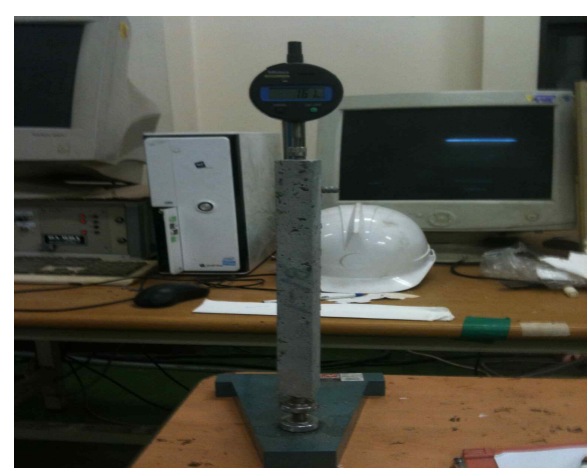

Figure 8. Measurement of expansion ratio

Autoclave expansion rates of electric arc furnace oxidizing slag and reducing slag were compared in Table 10 and Figure 9.

ISO standard sand, EOS and ERS satisfy the standard of stability, expansion under $0.35 \%$ as indicated in KS F 2580 steel slag. Among them, ISO standard sand and EOS stopped expansion at the pressing time of 36 hours. While there is a slight difference, the ISO standard sand and EOS stopped expansion in similar ways.

When replacing ERS with EOS $10 \%, 20 \%$, and $30 \%$, it stopped expansion at 72 hours after the start of pressurization. If replacing electric arc 
furnace reducing slag, it showed expansion due to the high basicity of 2.12 in the slag aggregate so that it took two more days for expansion to stabilize compared to the electric arc furnace oxidizing slag.

In addition, EOS showed a lower length variation than ESR. It was found out that electric arc furnace oxidizing slag without expansion was also stable and could be used as the construction materials as a result of pressurization.

Table 10. Comparing of autoclave expansion

\begin{tabular}{ccccccc}
\hline \multirow{2}{*}{ Type } & \multicolumn{6}{c}{ Curing Time(Hour) } \\
\cline { 2 - 7 } & 0 & 12 & 24 & 36 & 48 & 72 \\
\hline ISO-Sand & 0 & 0.100 & 0.160 & 0.180 & 0.180 & 0.180 \\
EOS & 0 & 0.130 & 0.190 & 0.210 & 0.210 & 0.210 \\
ERS 10 & 0 & 0.150 & 0.220 & 0.265 & 0.280 & 0.280 \\
ERS 20 & 0 & 0.155 & 0.215 & 0.275 & 0.290 & 0.290 \\
ERS 30 & 0 & 0.155 & 0.225 & 0.280 & 0.297 & 0.297 \\
\hline
\end{tabular}

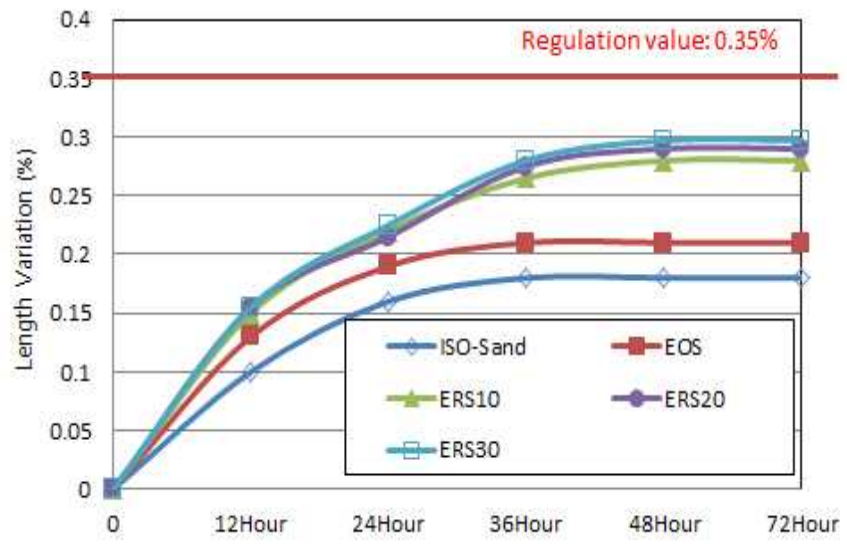

Figure 9. Comparing of autoclave expansion

Figure 10 showed the difference of the length variation according to the EOS-ERS substitution rate.

The higher the mixing of ERS is, the higher the length variation appears. When ISO standard sand is used, length variation is $0.18 \%$, and the specimen without ERS mixing showed length variation of about $0.2 \%$, showing about $0.02 \%$ difference.

On the other hand, according to Figure 10, as the substitution rate of ERS increased to $10 \%, 20$ $\%$, and $30 \%$, the length variation rate increased to $0.27 \%, 0.28 \%$, and $0.29 \%$. It was found out that specimen could be expanded if a higher substitution rate of ERS with expansion was used for mixing.

Since a separate discharge facility is not ready at the slag open yard where electric arc furnace slag is discharged, EOS and ERS are not separated but extracted while they are attached on the same aggregate. If aggregate is used while it is attached as it is without separate discharge of EOS and ERS, it may result in the collapse of building with expansion depending on the amounts of electric arc furnace reducing slag.

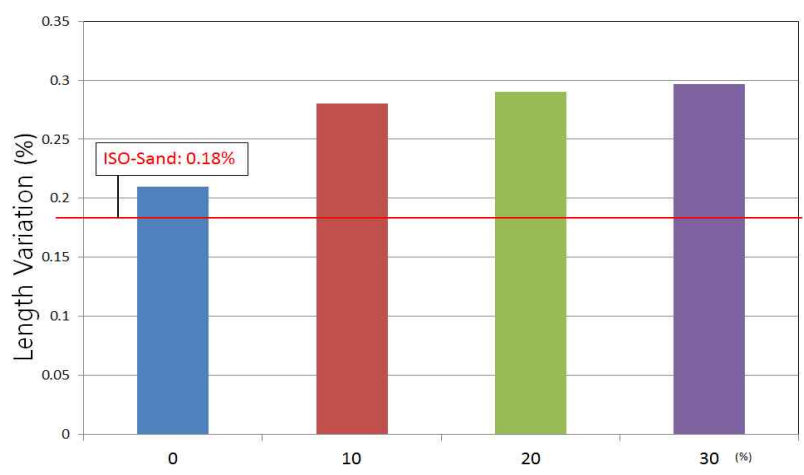

Figure 10. Length variation due to the ERS replacement ratio

\subsection{Comparison of Steel Slag $80{ }^{\circ} \mathrm{C}$ Immersion Expansion and Autoclave Experiment}

In $80{ }^{\circ} \mathrm{C}$ immersion expansion experiment of steel slag according to KS F 2580, mortar specimen for length change created in section 3.4 was used the same as the autoclave experiment. The Length variation was measured using the mortar length variation dial gauge for 10 days under the same conditions after taking out from $80{ }^{\circ} \mathrm{C}$ water and lowering the specimen to $20{ }^{\circ} \mathrm{C}$. 
If ISO standard sand was used as shown in Table 11 and Figure 11, expansion stopped on the day 2 of curing. While EOS stopped expansion on the day 4 of curing, ERS10 ERS20 ERS30 stopped expansion on the day 5 of curing. Specimens mixed with the same ERS showed lower expansion and the expansion stopped more quickly if the mixing rate of ERS was lower.

The reason why $80{ }^{\circ} \mathrm{C}$ immersion expansion results of steel slag showed a similar tendency as the experiment results of autoclave expansion is because it has no expansion due to low basicity in EOS. Expansion ended more quickly and satisfied the standard value less than 0.35 in comparison with the case of ERS replacement.

Table 11. Immersion expansion ratio(\%)

\begin{tabular}{ccccccccccc}
\hline & \multicolumn{10}{c}{ Day } \\
\cline { 2 - 11 } & 1 & 2 & 3 & 4 & 5 & 6 & 7 & 8 & 9 & 10 \\
\hline ISO-Sand & 0 & 0.01 & 0.01 & 0.01 & 0.01 & 0.01 & 0.01 & 0.01 & 0.01 & 0.01 \\
EOS & 0 & 0.02 & 0.03 & 0.05 & 0.05 & 0.05 & 0.05 & 0.05 & 0.05 & 0.05 \\
ERS 10 & 0 & 0.01 & 0.02 & 0.03 & 0.03 & 0.03 & 0.03 & 0.03 & 0.03 & 0.03 \\
ERS 20 & 0 & 0.01 & 0.02 & 0.02 & 0.05 & 0.05 & 0.05 & 0.05 & 0.05 & 0.05 \\
ERS 30 & 0 & 0.01 & 0.03 & 0.05 & 0.06 & 0.06 & 0.06 & 0.06 & 0.06 & 0.06 \\
\hline
\end{tabular}

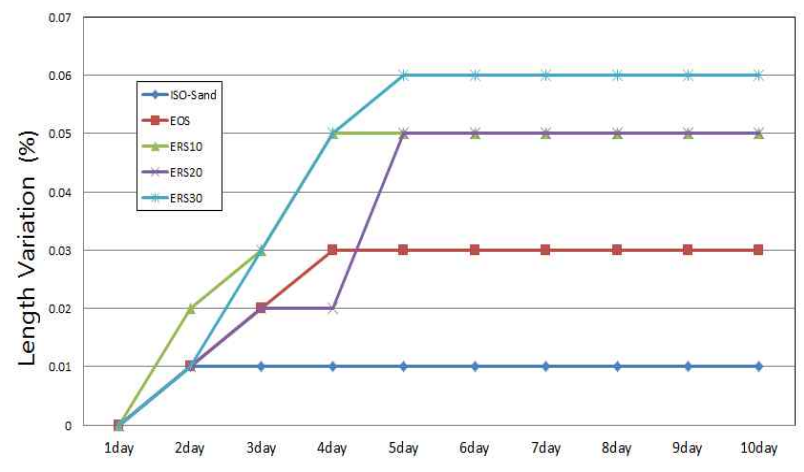

Figure 11. Immersion expansion accumulated ratio (\%)

Figure 12 shows the basicity and the length variation rate. It showed the basicity $\left(\mathrm{CaO} / \mathrm{SiO}_{2}\right)$ relation of EOS and ERS10, ERS20, and ERS30 when it is 36 hours old through the immersion expansion experiment and autoclave experiment, which are physical analysis as well as the basicity of chemical analysis.

It was found out that the length variation rate decrease as the basicity decreased and that length variation also decreased as the basicity decreased in the graph of the relationship between the basicity and the length change rate proposed at JIS A 5011.

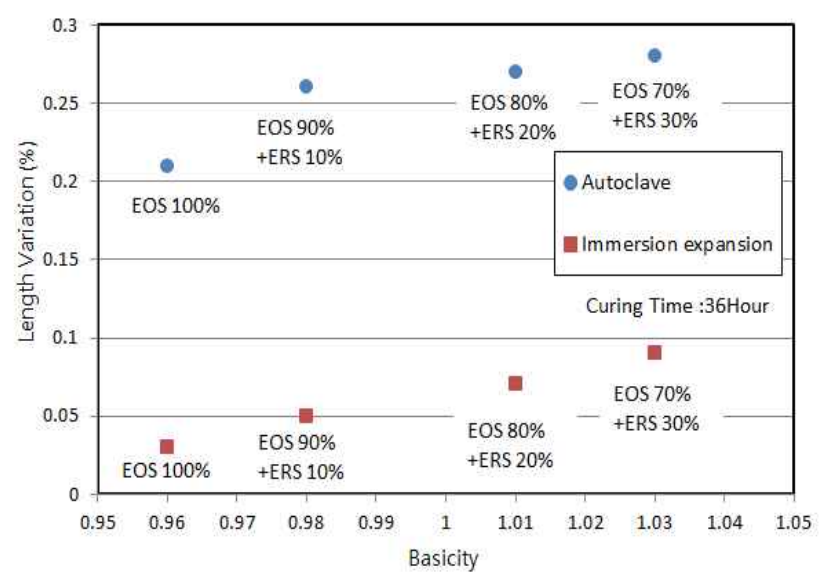

Figure 12. The relationship between the length variation and basicity

\subsection{Analysis of Quick Expansion of EOS}

The timing of EOS and ERS expansion could be identified through the steel slag $80{ }^{\circ} \mathrm{C}$ Immersion Expansion experiment and the autoclave expansion experiment performed to examine the physical feature. Figure 13 shows the comparison of the evaluation time of the autoclave expansion experiment with that of Immersion expansion.

While expansion stops on day 2 if it is based on EOS in the autoclave expansion experiment so that expansion stop determination can be made, expansion stop determination can be made in about 4 days later the $80{ }^{\circ} \mathrm{C}$ Immersion Expansion experiment.

In the present, it is not required to supplement the insufficient open yard and the EOS quality can be guaranteed if the expansion for about 2 days is determined, compared to the situation that it is 
used after 3 months of aging at the open yard of electric arc furnace oxidizing slag.

Accordingly, it is considered that the prompt evaluation of expansion can be made using the autoclave expansion experiment instead of the immersion expansion experiment currently used, as shown in the comparison of fast expansion of Figure 13.

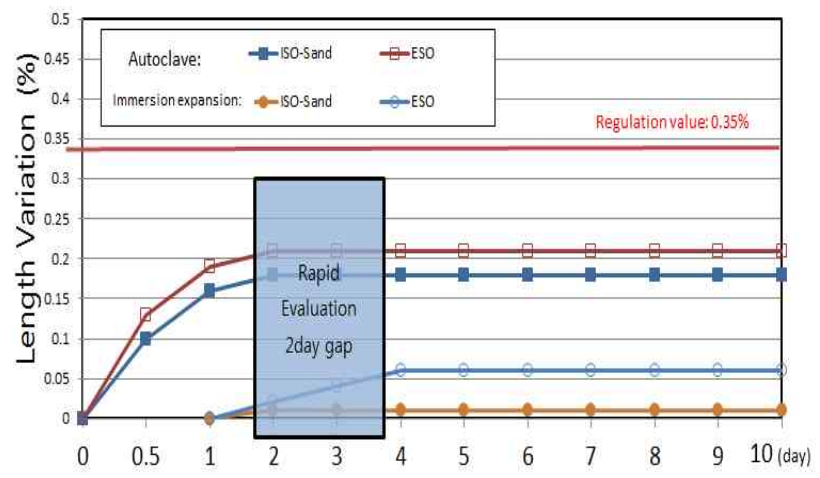

Figure 13. Comparing of the assessment time for autoclave expansion and the immersion expansion

\section{Conclusion}

During this study of using electric arc furnace oxidizing slag and electric arc furnace reducing slag, the experiment was conducted on the evaluation of durability and mechanical performance in order to prepare the foundation for the utilization of fine aggregate for concrete. Following results were obtained.

1) It could be predicted with the $X R F$ basicity that electric arc furnace oxidizing slag has no expansion due to low basicity compared to electric arc furnace reducing slag .

2) As a result of analyzing expansion through the $80{ }^{\circ} \mathrm{C}$ immersion expansion experiment and the autoclave experiment using electric arc furnace oxidizing slag and electric arc furnace reducing slag as fine aggregate, fine aggregate of electric arc furnace oxidizing slag was found to have almost no expansion.

3) While expansion within about 4 days can be determined with current Immersion Expansion experiment through the comparison and analysis of fast expansion experiment of electric arc furnace oxidizing slag, expansion within about 2 days can be determined with autoclave expansion experiment. Accordingly, since the time of about 2 days can be shortened if the autoclave expansion experiment is performed, the utilization of electric arc furnace oxidizing slag can be expanded further.

\section{Acknowledgement}

This research was supported by a grant(10035222, 100014051) by Ministry of Knowledge Economy of Korean government, SUSB Research Centre of Hanyang University by ERC program of MEST(\#R11-2005-056-04003-0)

\section{References}

1. Crude steel E.A.F, Korea Iron \& Steel Association [internet]. [updated 2011 April 11] Available from :http://www.kosa. or.kr/statistics / production_2011.jsp\#

2. Kim KH, Lim JY, Ryu DH, Choi SW. The Present Situation of Production and It's Utilization of Electronic Arc Furnace Oxidizing Slag in Korea and Other Countries. Journal of the Korea Concrete Institute. 2007 Nov;19(6):51-7.

3. Korean Industrial Standard. [Electric Arc Furnace Oxidizing Slag Fine Aggregate for Concrete(KS F 4571)]. Korea, Korean Industrial Standards; 2007. Korean.

4. Kwak EG, Kim JM. Evaluation of Application for the Concrete Aggregate of Electric Arc Furnace Oxidizing Slag Treated by Rapidly Cooling Method. Journal of the Architectural Institute of Korea: Structure \& Construction. 2010 Feb;26(2):63-70.

5. Architectural Institute of Japan. [Recommendation for Practice of Concrete with Electric Arc Furnace Oxidizing Slag Aggregate]. 1st Ed. Tokyo (Japan): Architectural Institute of 
Japan Pub; 2005. 122 p. Japanese.

6. Choi SW, Kim V, Chang WS, Kim EY. The Present Situation of Production and Utilization of Steel Slag in Korea and Other Countries. Journal of the Korea Concrete Institute. 2007 Nov;19(6):28-33.

7. Kim SM, Park WJ, Lee HH, Kim KH. Study on Utilization of Electric Arc Furnace Oxidizing Slag as Fine Aggregates for Cement Concrete. Journal of the Korean Society of Civil Engineers. 2008 May;28(3A):407-15.

8. Kim JM, Cho SH, Oh SY, Kwak EG. Properties of Rapidly-Cooled Steel Slag by Atomizing Process. Journal of the Korea Concrete Institute. 2007 Nov;19(6):39-45.

9. Ryu DH, Kim, KH Park CG, Son YS. The Study of Concrete Basic Properties Using Oxidized Electric Furnace Slag Aggregate. Journal of the Architectural Institute of Korea: Structure \& Construction. 2009 Aug;25(8):143-50.

10. Yoo JH, Choi JJ. Pending Problems and Potentialities of Iron Slag for Concrete Aggregate. Journal of the Korea Concrete Institute. 2007 Nov;19(6):34-8.

11. Korean Industrial Standard. [Methods of Testing CementsDetermination of Strength(KS L ISO 679)]. Korea, Korean Industrial Standards; 2006. Korean.

12. Korean Industrial Standard. [Testing Method for Autoclave Expansion of Portland Cement(KS L 5107)]. Korea, Korean Industrial Standards; 2001. Korean.

13. Korean Industrial Standard. [Test Method of the Immersion Expansion in $80{ }^{\circ} \mathrm{C}$ Water of the Iron and Steel Slag(KS F 2580)]. Korea, Korean Industrial Standards; 2007. Korean. 